\title{
A Patient with a Benign and a Malignant Primary Pulmonary Meningioma: An Evaluation with 18F Fluorodeoxyglucose Positron Emission Tomography/Computed Tomography and Computed Tomography with lodinated Contrast
}

\begin{abstract}
An 80 -year-old male with a previous history of thymoma and kidney cancer underwent a ${ }^{18} \mathrm{~F}$ fluorodeoxyglucose (FDG) positron emission tomography (PET)/contrast-enhanced computed tomography (CT) scan: two pulmonary nodules were discovered, both characterized by an increased glucose uptake. Of them, only one showed mild contrast enhancement. Both nodules were surgically resected: the first nodule was a benign meningioma and the second one was a malignant meningioma. This case study shows that malignancy of meningioma in the lung is not correlated with ${ }^{18} \mathrm{~F}$ FDG uptake and the contrast enhancement, thus suggesting that PET/CT may represent a suboptimal imaging modality for the evaluation of these lesions.
\end{abstract}

Keywords: $18 F$ fluorodeoxyglucose, ectopic meningioma, iodinated contrast enhancement, malignant meningioma, pulmonary nodule

\section{Introduction}

Ectopical meningiomas (extracranial meningiomas) are extremely rare: despite being one of the most frequently diagnosed primary intracranial tumors, meningioma rarely occurs in several locations such as the head-and-neck region, skin, bone, peripheral nerves, retroperitoneum, and lung. ${ }^{[1,2]}$ Different histogenetic and pathologic mechanisms have been proposed, but the true etiology of this tumor is still uncertain: ${ }^{[3]}$ Some authors believe that extracranial meningioma might derive from misplaced or migrate arachnoid cells, other investigators have revealed that the tumor may originate from perineurial cells or pluripotent mesenchymal cells. ${ }^{[2]}$

The first reported case of primary pulmonary meningioma (PPM) was in 1982. ${ }^{[4]}$ To the best of our knowledge, till date, only 44 cases have been reported in the literature: among these cases, only five were malignant or atypical. ${ }^{[1,2]}$

\section{Case Report}

An 80-year-old male, from whom we obtain the consent form, during the follow-up

This is an open access journal, and articles are distributed under the terms of the Creative Commons Attribution-NonCommercial-ShareAlike 4.0 License, which allows others to remix, tweak, and build upon the work non-commercially, as long as appropriate credit is given and the new creations are licensed under the identical terms.

For reprints contact: reprints@medknow.com for thymoma (previous thymectomy in 2011) and kidney cancer (previous nephrectomy in 2012), presented a solitary pulmonary nodule in the superior lobe of the right lung as detectable by means of ${ }^{18} \mathrm{~F}$ fluorodeoxyglucose (FDG) positron emission tomography (PET)/computed tomography (CT) scan in December 2015 (injected dose $380 \mathrm{MBq}$ ). PET/CT images showed a metabolically active lesion (SUVmax $4.63 \mathrm{~g} / \mathrm{ml}$ bw, $14 \mathrm{~mm}$ in diameter), suspected of being a metastasis [Figure 1]. Contrast-enhanced CT with iodinated contrast media performed after PET examination did not show significant attenuation between pre- and postcontrast phase [Figure 2]. After a right pulmonary resection in January 2016, bioptic diagnosis of the nodule was compatible with fibrotic (benign) pulmonary meningioma.

In June 2016, another ${ }^{18} \mathrm{~F}$ FDG PET/CT scan was performed in the same patient (injected dose $361 \mathrm{MBq}$ ) that showed another new metabolically active pseudonodular lesion (SUVmax $2.46 \mathrm{~g} / \mathrm{ml} \mathrm{bw}, 12 \mathrm{~mm}$ in diameter) in the superior lobe of the left

How to cite this article: Cimini A, Ricci F, Pugliese L,
Chiaravalloti A, Schillaci O, Floris R. A patient with a
benign and a malignant primary pulmonary meningioma:
An evaluation with $18 \mathrm{~F}$ fluorodeoxyglucose positron
emission tomography/computed tomography and
computed tomography with iodinated contrast. Indian
J Nucl Med 2019;34:45-7.

\section{Andrea Cimini ${ }^{1}$, Francesca Ricci ${ }^{1}$, Luca Pugliese1, Agostino Chiaravalloti ${ }^{1,2}$, Orazio Schillaci ${ }^{1,2}$, Roberto Floris ${ }^{1}$}

${ }^{1}$ Department of Biomedicine and Prevention, University Tor Vergata, Rome, ${ }^{2}$ Department of Nuclear Medicine IRCSS, Neuromed, Pozzilli, Italy

Address for correspondence: Dr. Andrea Cimini, University Tor Vergata, Viale Oxford 81,

00133, Rome, Italy. E-mail: andreacimini86@ yahoo.it

Access this article online Website: www.ijnm.in DOI: 10.4103/ijnm.IJNM_101_18 Quick Response Code:

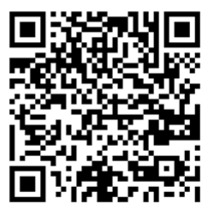






Figure 1: Positron emission tomography/computed tomography image of the fibrous (benign) pulmonary meningioma

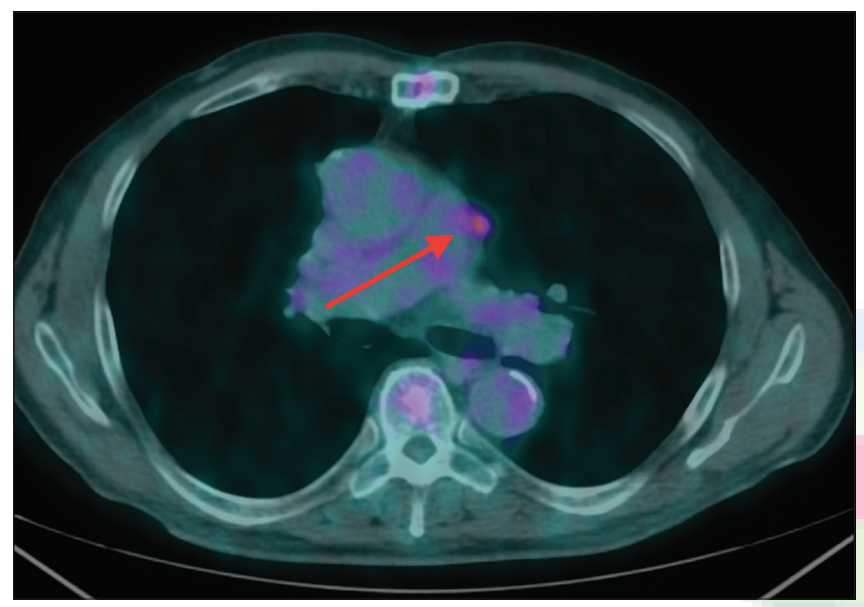

Figure 3: Positron emission tomography/computed tomography image of the malignant pulmonary meningioma

lung [Figure 3]. A CT scan with iodinated contrast, the lesion showed enhancement at postcontrast phase [basal scan:-1 HU; postcontrast scan: $55 \mathrm{HU}$, Figure 4]. After an atypical resection of the superior lobe of the left lung in September 2016, biopsy showed a high proliferative activity with a number of mitotic figures $>20 / 10 \mathrm{HPF}, \mathrm{Ki}-67 \approx 20 \%$, with associated necrosis and on immunohistochemistry cells expressed epithelial membrane antigen and they were positive for vimentin and progesterone: the final diagnosis was anaplastic meningioma (malignant).

\section{Discussion}

To the best of our knowledge, this is the first ${ }^{18} \mathrm{~F}$ FDG PET/CT evaluation of a patient with synchronous benign and malignant PPM, with similar dimensions (14 and $12 \mathrm{~mm}$ in diameter): qualitative and semi-quantitative (SUVmax) analysis with PET suggested less metabolic activity in malignant PPM, with more intense uptake of ${ }^{18} \mathrm{~F}$ FDG in fibrotic PPM. Furthermore, anaplastic meningioma showed enhancement with iodinated contrast media. From this case report, we conclude that ${ }^{18} \mathrm{~F}$ FDG PET may not suffice in the evaluations of patients with PPM; the conjunction with contrast-enhanced CT

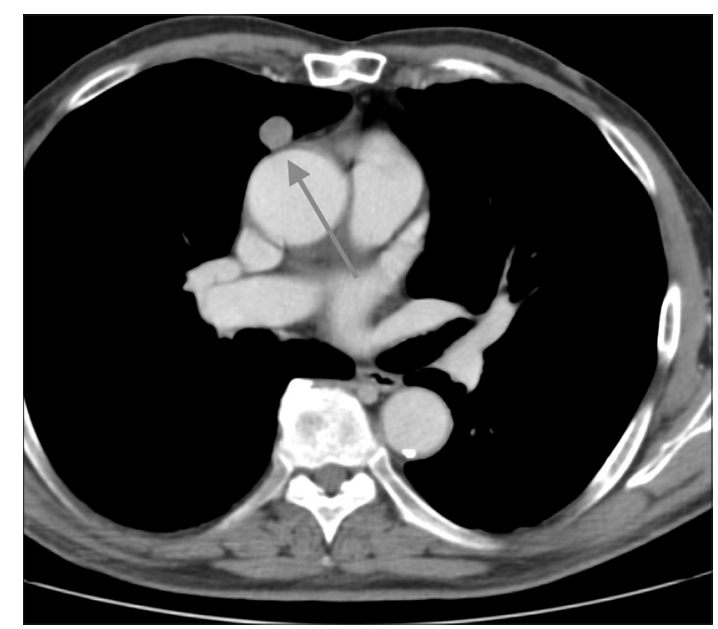

Figure 2: Contrast-enhanced computed tomography image of the fibrous (benign) pulmonary meningioma

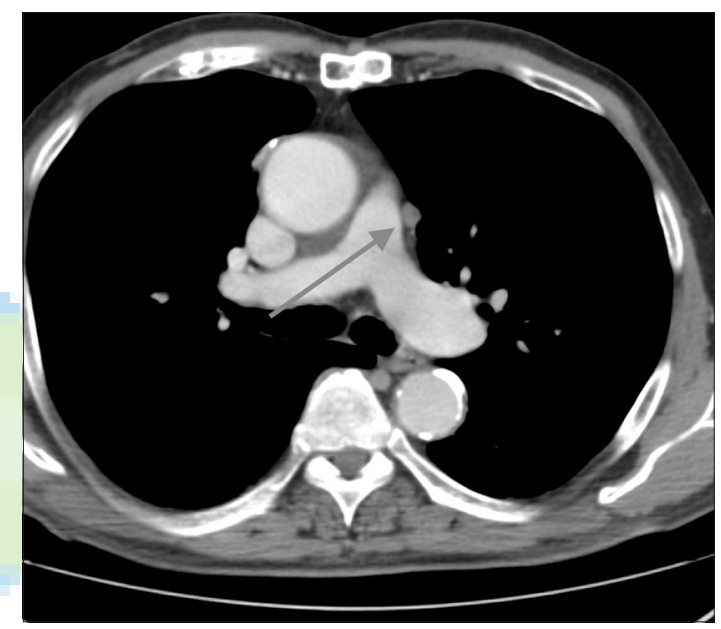

Figure 4: Contrast-enhanced computed tomography image of malignant pulmonary meningioma

may help in the discrimination between malign and benign lesions. Furthermore, due to high levels of expression of the somatostatin receptor subtype 2 in meningiomas, the use of other radiolabeled compounds (i.e., ${ }^{68} \mathrm{Ga}$-DOTATOC $\mathrm{PET} / \mathrm{CT}^{[1,5]}$ ) may be more useful for this aim.

\section{Declaration of patient consent}

The authors certify that they have obtained all appropriate patient consent forms. In the form the patient(s) has/have given his/her/their consent for his/her/their images and other clinical information to be reported in the journal. The patients understand that their names and initials will not be published and due efforts will be made to conceal their identity, but anonymity cannot be guaranteed.

\section{Financial support and sponsorship}

Nil.

\section{Conflicts of interest}

There are no conflicts of interest. 


\section{References}

1. Kim YY, Hong YK, Kie JH, Ryu SJ. Primary pulmonary meningioma: An unusual cause of a nodule with strong and homogeneous enhancement. Clin Imaging 2016;40:170-3.

2. Mao YQ, Zhang W, Yin WJ, Zhu SX. Primary ectopic atypical meningioma in the renal hilum: A case report. BMC Cancer 2014;14:763.

3. Lepanto D, Maffini F, Petrella F, Colandrea M, Putzu C, Barberis $\mathrm{M}$, et al. Atypical primary pulmonary meningioma:
A report of a case suspected of being a lung metastasis. Ecancermedicalscience 2014;8:414.

4. Kemnitz P, Spormann H, Heinrich P. Meningioma of lung: First report with light and electron microscopic findings. Ultrastruct Pathol 1982;3:359-65.

5. Caobelli F, Facchetti F, Pizzocaro C, Ferrari V, Savelli G, Guerra UP, et al. A very unusual and aggressive form of a primary pulmonary meningioma seen with a ${ }^{68} \mathrm{Ga}$-DOTATOC PET/CT image. Rev Esp Med Nucl Imagen Mol 2015;34:123-4. 